\title{
Aprendizagem ao longo da vida e capacitação digital dos adultos idosos
}

\author{
Henrique Teixeira Gil ${ }^{*}$
}

\begin{abstract}
Resumo
O aumento da esperança de vida tem tido como consequência um gradual envelhecimento da sociedade, sendo os adultos idosos com 65 anos ou mais, aqueles que mais têm vindo a aumentar nos países mais desenvolvidos. Esta realidade fez com que exista um maior número de reformados que receberam a sua formação num contexto muito diferente do atual. Como é por demais evidente, o avanço das tecnologias digitais e suas aplicações, têm promovido alterações nas rotinas diárias dos cidadãos. No presente contexto, torna-se pertinente uma discussão crítica e reflexiva acerca do papel da aprendizagem ao longo da vida e dos requisitos para uma adequada capacitação digital no sentido de se providenciarem condições para uma mais ajustada inclusão social dos adultos idosos.
\end{abstract}

Palavras-chave: Adultos idosos. Aprendizagem ao longo da vida. Infoinclusão. Inclusão social. Literacia digital.

\section{Realidades e tendências da globalização}

No mundo cada vez mais global, as sociedades nos países mais desenvolvidos mostram uma tendência clara para um gradual e progressivo aumento do envelhecimento. Esta realidade é consequência direta de um aumento generalizado da esperança média de vida acompanhada dos avanços da medicina que, de acordo com dados da WHO (2018), já fez com que a esperança média de vida se situasse em 2016 nos 72 anos de idade. Este valor é facilmente ultrapassado no seio da EU-28, cujo valor já se situa em $80+$ anos de idade na grande maioria dos seus países. A Figura 1, de acordo com dados do Eurostat (2016), apresenta a pirâmide etária onde se comparam os dados por sexo no seio da E-28 e os dados mundiais, onde se torna clara a tendência para uma configuração em forma de 'urna' pelo aumento progressivo da população mais idosa. Talvez o dado mais significante tem a ver com o facto de ser a faixa etária de $80+$ anos aquela que evidencia um maior crescimento.

\footnotetext{
* Pós-doutorado em Política Social, Universidade de Lisboa, Instituto Superior de Ciências Sociais e Políticas, Lisboa/Portugal. Doutorado em Educação, University of Exeter, School of Education, United Kingdom. Docente do Instituto Politécnico de Castelo Branco, Castelo Branco/Portugal. E-mail: hteixeiragil@ipcb.pt.
} http://dx.doi.org/10.5335/rbceh.v16i3.10258 
Figura 1 - Pirâmide de idades relativas ao ano de 2014 com dados comparativos entre a EU-28 e o Resto do Mundo.

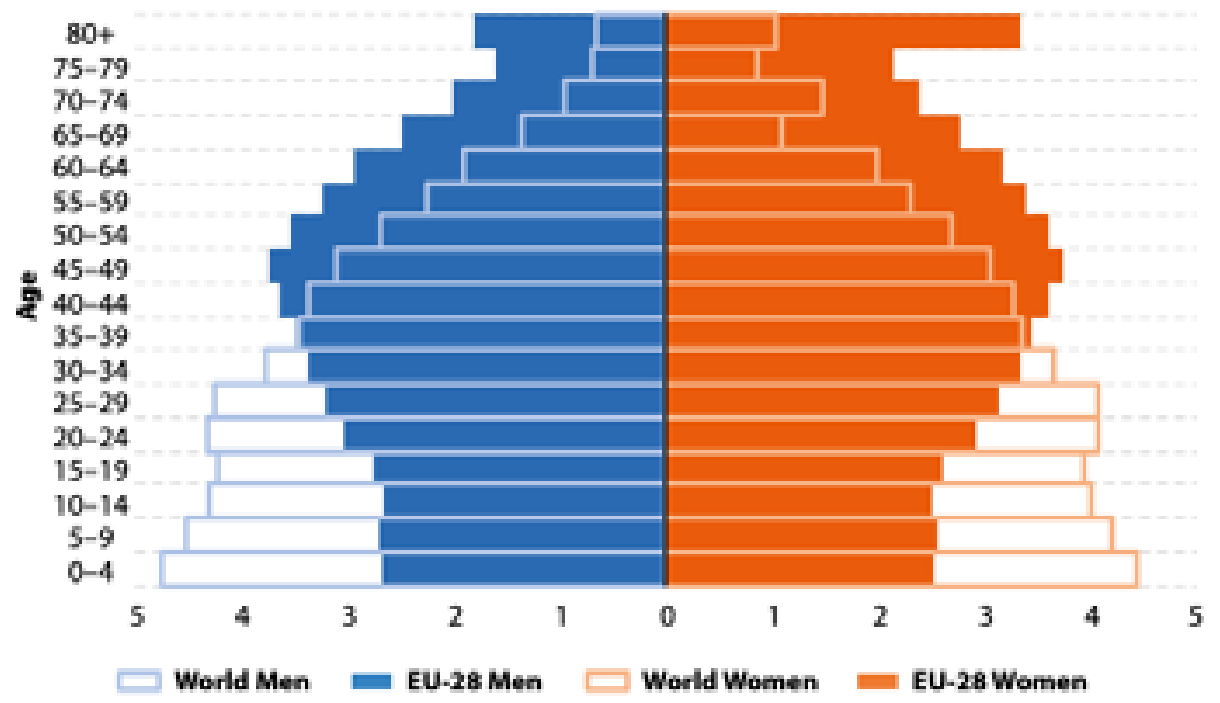

Fonte: Eurostat (2016).

Como forma de poder dar uma visão mais clara e complementar, a Figura 2 com dados do Eurostat (2016), apresenta os valores relativos ao índice de dependência dos idosos entre vários países onde se pretende destacar os valores médios da EU-28 e os valores mundiais. Como se pode observar, quer na EU-28 quer a nível mundial, este índice foi aumentando entre os anos de 1960 a 2014, tendo esse valor duplicado na EU-28 mas com a agravante das projeções para 2060 indicarem o valor de $50 \%$, que significa um altíssimo índice de envelhecimento. 
Figura 2 - Valores correspondentes ao índice de dependência de idosos correspondentes aos anos de 1960 e de 2014 e projeções para o ano 2060

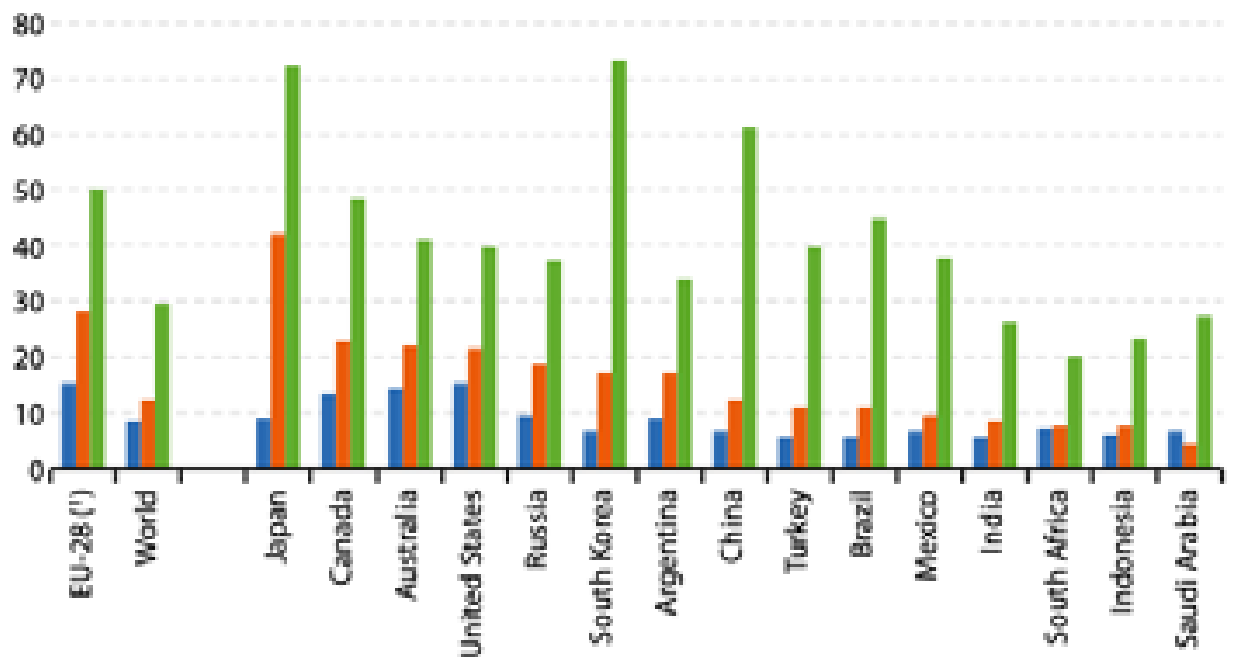

Fonte: Eurostat (2016).

Em termos práticos, este prolongamento da esperança de vida vem fazer com os adultos idosos continuem a realizar as suas atividades, mas numa sociedade e em contextos muito diferentes daqueles onde exerceram a sua atividade profissional. Associado a este desfasamento .não se pode esquecer a formação adquirida que foi projetada para uma sociedade que já não existe, para uma sociedade onde o digital era muito incipiente. Pelo contrário, estes adultos idosos estão hoje confrontados com uma nova realidade onde o digital impera e que faz com que praticamente todas as rotinas sejam concretizadas através da manipulação de tecnologias, de plataformas digitais e de serviços mediados por procedimentos digitais. Assim sendo, é fundamental que existam políticas associadas à aprendizagem ao longo da vida que permitam uma contínua formação dos cidadãos e, em especial, dos adultos idosos em áreas que lhes permitam usufruir das oportunidades e de poderem exercer, na plenitude, os seus direitos e deveres cívicos. Neste particular, torna-se pertinente e necessária uma forte componente em literacia digital para que a utilização dos recursos e das ferramentas digitais possam ser feitos sem constrangimentos e na sua plenitude. A Figura 3 permite ter presente uma informação global correspondente ao ano de 2017, à escala mundial, acerca das percentagens de utilização da Internet por cidadãos até aos 
15 anos de idade e por cidadãos com 65+ anos de idade (STATISTA, 2017). Como se pode facilmente observar, os adultos idosos apresentam percentagens de utilização fracamente reduzidas. Estes factos têm forçosamente uma implicação direta na qualidade de vida dos adultos idosos pelo seu alto nível de infoexclusão que lhes obstaculiza e lhes compromete seriamente o acesso e ao exercício de uma cidadania plena. Quer isto dizer, que não se consegue uma total e global inclusão social com todos os prejuízos e consequências que acarreta esta penosa realidade.

Figura 3 - Percentagem de utilização da Internet no ano de 2017, à escala mundial, na faixa etária inferior aos 15 anos de idade e para faixas etárias com 65 anos ou mais

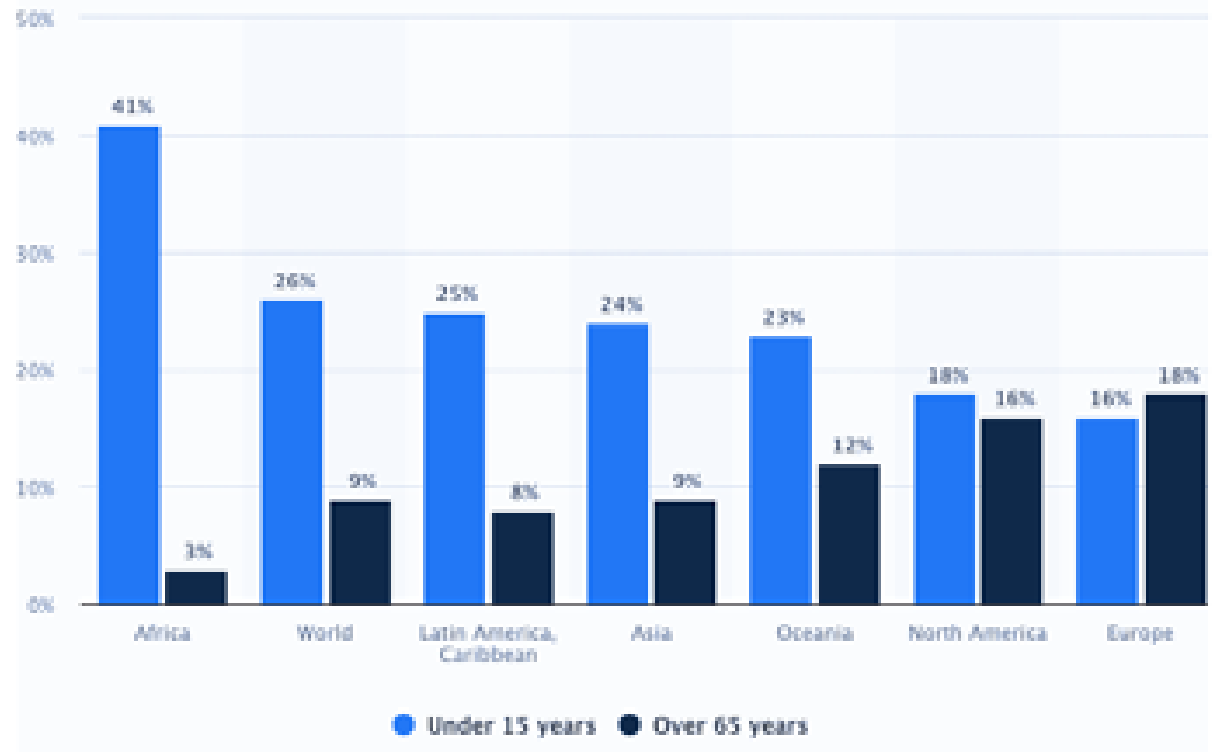

Fonte: Statista (2017).

Pelas razões já referenciadas, é importante que se faça uma reflexão acerca da aprendizagem ao longo da vida, dos conceitos que lhe estão associados e das medidas ou propostas preconizadas e em curso. Por outro lado, é também necessária uma reflexão crítica acerca das diferentes concepções associadas à literacia digital e às suas repercussões nas rotinas dos adultos mais idosos.
Por último, há também a necessidade de se refletir acerca da problemática da infoexclusão dos adultos idosos e as respetivas consequências que põem em causa a sua inclusão social para que se possam criar pistas que revertam esta presente situação e que urge reverter. 


\section{Aprendizagem ao longo da vida: Que diretivas!?}

No meio académico o contraditório e a reflexão são uma constante que deve ser estimulada e incentivada para que surjam novas e diferentes interpretações que permitam espaços mais criativos e inovadores. Na presente Sociedade do Conhecimento, esta realidade é cada vez mais primordial no estímulo de discussões acerca de conceitos que podem parecer demasiado unânimes. A aprendizagem ao longo da vida, pela sua importância estratégia, no sentido de poder 'moldar' os cidadãos e de lhes promover novas e melhores condições não é exceção. Há um aforismo popular português que refere o seguinte: Aprender até morrer! É neste sentido que se vai refletir acerca deste direito em aprender ao longo de toda uma vida, desde que se nasce até que se morre, no sentido de poder propor soluções para os problemas quotidianos e, desta forma, proporcionar todas as condições necessárias e suficientes para uma cidadania participada.

Quando se pretende definir o conceito de Aprendizagem ao longo da vida, concorda-se com Sitoe (2006) ao referir que inclui qualquer atividade, em qualquer que seja o momento da vida em que possa ocorrer, desde que tenha como objetivo a melhoria, a ampliação ou aprofundamento de conhecimentos, de aptidões e de competências, em diferentes níveis (pessoais, cívicos e sociais) que possam ter ou não uma relação com o emprego ou atividade profissional. É nesta relação e dimensão com o mundo do trabalho que Guimarães (2016) chama à atenção para uma visão mais neoliberal no sentido de se visar mais uma oportunidade de cariz económico e produtivo em detrimento de uma visão mais humanista e mais centrada nos indivíduos. Aliás, esta visão mais economicista é também referenciada por Lima (2005) como se tratando de se tornar a aprendizagem ao longo da vida como um instrumento associado às políticas de economia social e do trabalho. Ou seja, uma aprendizagem ao longo da vida vocacionada para o crescimento económico das empresas e do Estado e, desta forma, proporcionar a manutenção dos trabalhadores no seu posto de trabalho. Esta concepção tem vindo a ser apresentada e ratificada pela Comissão Europeia e foi publicado um Quadro de Referência Europeu com a identificação das competências essenciais para a aprendizagem ao longo da vida (COMUNIDADES EUROPEIAS, 2007), no sentido de cada cidadão se poder adaptar com uma maior facilidade num mundo em constante mutação e profundamente globalizado:

1. Comunicação na língua materna;

2. Comunicação em línguas estrangeiras;

3. Competência matemática e competências básicas em ciências e tecnologia;

4. Competência digital;

5. Aprender a aprender;

6. Competências sociais e cívicas;

7. Espírito de iniciativa e espírito empresarial; 
8. Sensibilidade e expressão culturais.

Apesar de nos objetivos da Comissão Europeia terem como prioridade cidadãos com um baixo nível de literacia, jovens em situação e abandono escolar precoce, desempregados de longa duração, aqueles que regressaram ao trabalho após um período de licença prolongado e também para os idosos, para os migrantes e para as pessoas com deficiência. Uma iniciativa da Comissão das Comunidades Europeias (2001) com o lema Tornar o espaço europeu de aprendizagem ao longo da vida uma realidade faz uma apreciação global da necessidade da implementação de medidas e de estratégias conducentes à concretização de uma aprendizagem ao longo da vida que possa congregar, sem exceção, todos os cidadãos.

Contudo, o conteúdo do documento, apesar de referenciar a necessidade de se aproximar a aprendizagem e os aprendizes e de se proporem pedagogias inovadoras que incluíam as seguintes preocupações: facilitar o acesso às oportunidades de aprendizagem; fomentar uma cultura da aprendizagem; valorizar a aprendizagem; fomentar o trabalho em parceria. Há, de facto, a menção escrita de se promover a transição do conhecimento para a competência e do ensino para a aprendizagem ao se conferir aos aprendizes o papel central. No entanto, sente-se uma grande preocupação que, de certa forma, coloca em causa estes objetivos. Pois, o que parece ser prioritário é colocar a aprendizagem ao longo da vida ao serviço da qualificação dos trabalhadores e na formação de forma a tornar a União Europeia mais competitiva através da criação de uma maior empregabilidade para estes cidadãos ativos.

A leitura atenta do Plano de Acção para a Educação de adultos - Nunca é Tarde para Aprender começa na sua introdução por referir as deliberações do Conselho Europeu de Lisboa, ocorrido em 2000, onde se reconhece a necessidade da “(...) promoção da empregabilidade e da inclusão social através de um investimento nos conhecimentos e nas competências dos cidadãos em todas as fases das suas vidas." (COMISSÃO DAS COMUNIDADES EUROPEIAS, 2007, p. 2) O mesmo documento refere ainda o programa Educação e Formação para 2010 onde se reportam os benefícios e a importância do investimento na educação com vista a uma maior oportunidade de empregabilidade e num maior e mais vasto leque de melhorias sociais, económicas, políticas, culturais e onde também se incluem melhorias ao nível do bem-estar e realização pessoal. Há, de facto, uma referência ao indivíduo, mas o que se realça ao longo de todo o texto é uma grande ênfase na empregabilidade de forma a se poderem ter trabalhadores mais eficientes e poderem continuar a trabalhar onde, por exclusão de partes, se constata uma menor (ou até inexistente) preocupação com os adultos idosos já reformados. Como se pode verificar na Figura 4, constante como anexo acerca da Educação de adultos: nunca é tarde para aprender, os dados evidenciam de forma bastante clara a mais reduzida 
participação dos adultos entre 56 a 64 anos em atividades associadas à aprendizagem ao longo da vida. E, como também se pode verificar, nem sequer existem dados para as faixas estarias com 65 anos ou mais, o que permite inferir não haver sequer uma preocupação no envolvimento destes adultos idosos neste processo de aprendizagem ao longo da vida.

Figura 4 - Participação em atividades de aprendizagem ao longo da vida por faixa etária correspondente ao ano de 2005 .

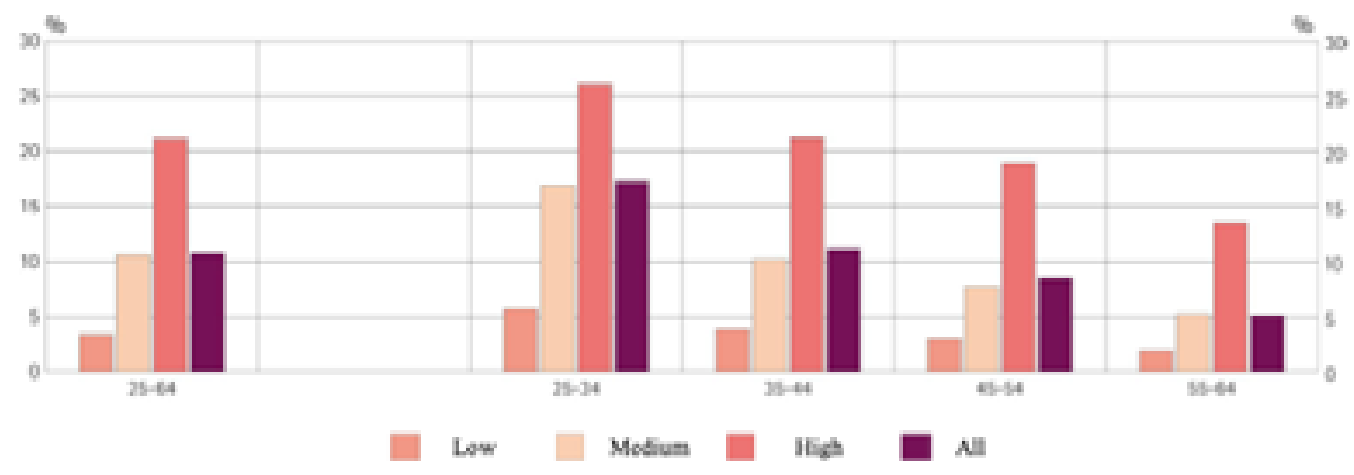

Fonte: Comissão das Comunidades Europeias (2006).

Na Figura 5 pode observar-se a percentagem de adultos que participaram em ações de aprendizagem ao longo da vida, por sexo, na EU-28 e que se reportam ao ano de 2016 (CONSELHO NACIONAL DE EDUCAÇÃO, 2016), onde se constata uma fraca percentagem de adesão. Pois, dos 28 países apenas 8 conseguem atingir a meta estabelecida para o ano de 2020. Da informação disponibilizada não é possível aferir-se quais as razões para estas percentagens tão baixas pelo que se pode especular se estas terão a ver com falta de incentivos, com a falta de um proveito imediato (exemplo: progressão nas carreiras profissionais) ou pela falta de uma cultura de aprendizagem ao longo da vida. Mas, nesta sociedade tão competitiva, os va- lores apresentados parecem ser preocupantes não apenas no âmbito econômico, mas também no âmbito social. 
Figura 5 - Percentagem de adultos que participaram em ações de aprendizagem ao longo da vida, por sexo, na EU-28 em 2016.

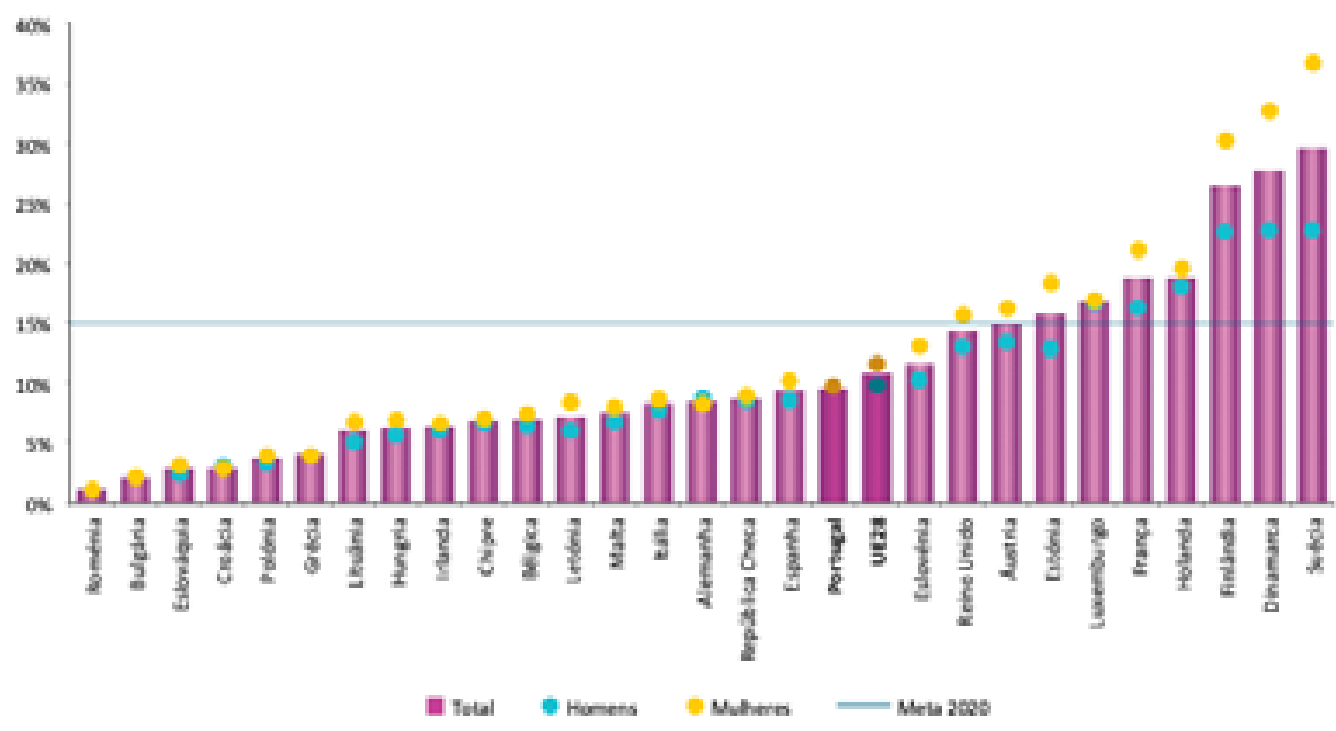

Fonte: Conselho Nacional de Educação (2016).

Mais recentemente, foi apresentado em 2017 o Report on a literature review of reforms related to the European Framework of key Competences for lifelong learning and the role of the framework in these reforms onde ressalta, de forma muito clara, que as atividades se processaram em contextos de uma aprendizagem formal devidamente certificada, com preocupações associadas à progressão de estudos no sentido de propiciar e facilitar o acesso ao mercado de trabalho e de poder dar resposta às futuras necessidades laborais (FOX et al., 2017).

Após a apresentação crítica e reflexiva acerca do que entende por aprendizagem ao longo da vida e dos seus efeitos práticos, fica uma sensação de algum ceticismo e de preocupação que é corroborada por Guimarães (2016, p. 46) ao se ter vindo a observar que as dimensões humanistas e de educação crítica, prioridades assumidas no século XIX, tenham vindo a ser substituídas por um enfoque económico e laboral, deixando de lado todo um vasto campo de "(...) políticas, práticas e de reflexão multifacetado e complexo com profundo significado para a consolidação da democracia, da justiça social e da igualdade de oportunidades." Ou seja, tudo aquilo que faz sentido para uma população mais idosa que necessita de espaços de aprendizagem contextualizada aos desafios presentes e que se tem negligenciado, ano após ano, dado que se privilegiam apenas os cidadãos ativos. Por essa razão, Sitoe (2006) chama à atenção para que a aprendizagem ao longo da vida inclua aprendizagens formais, não formais e informais, no 
sentido de se proporcionar uma inclusão de todas estas fases de aprendizagens, que acompanhem cada indivíduo desde a infância até à reforma. Mas Sitoe (2006, p. 288) complementa esta concepção ao assumir que a aprendizagem ao longo da vida deve ser uma extensão das aprendizagens adquiridas ao longo da vida ativa, continuando a aprender devendo ter meios "(...) para continuar a aprender, interagindo com o mundo e recebendo ajudas dos agentes de aprendizagem." Ou seja, permitir que se sintam socialmente incluídos e investidos dos seus direitos e deveres cívicos.

Neste sentido, Pacheco (2011) alerta para os perigos em se transformar a aprendizagem ao longo da vida numa lógica 'ortopédica de qualificação' quando se promove uma instrumentalização curricular dessas aprendizagens, no âmbito das designadas espacialidades sociais e normativas no sentido de dar cumprimento a meras metas estatísticas. Tal visão, como refere Pacheco (2011, p. 81), torna-se bastante redutora ao não priorizar e não valorizar as “(...) temporalidades e especialidades pessoais ou biográficas." Do mesmo modo, Pires (2007) também argumenta que se vem assistido a uma desvalorização dos processos de aprendizagem, no seu sentido mais funcional, a favor dos produtos e dos resultados dessas aprendizagens num sentido apenas do foro académico mais científico dentro de um paradigma mais clássico de ensino onde se enfatiza a certificação em vez da qualificação. Onde se privilegiam os objetivos de ensino e não as competências que podem vir a ser adquiridas. Como ainda refere Pacheco (2011), considerando a aprendizagem como um processo em devir, deve ser intemporal e, por isso mesmo, torná-la num elo de ligação entre gerações de acordo com os contextos sociais, económicos, políticos, religiosos, ideológicos e culturais. Por isso se apela a que esta aprendizagem ao longo da vida, tal como refere Lima (2005), possa e deva corresponder a aprendizagens úteis e socialmente eficazes numa comunidade de aprendizes. Deste modo, torna-se possível que estes aprendizes sejam autónomos e com um espírito crítico que permita a que cada um possa definir os seus projetos e priorizar as dinâmicas e as áreas das aprendizagens a atingir. Por isso, concorda-se com Pacheco (2011, p. 85) quando afirma que a aprendizagem ao longo da vida deva ser "(...) um itinerário de conhecimento." Do mesmo modo, Guercia (2001) afirma que se deve entender a educação num sentido que seja amplo que se ocupe de uma formação integral da pessoa e não a uma simples e mera técnica ou reciclagem profissional. Porque só desta forma a aprendizagem ao longo da vida poderá estar em conformidade com as necessidades e as expetativas dos adultos idosos. E, na presente sociedade cada mais assente no digital, importa perceber que competências são fundamentais a adquirir a fim de cada cidadão se poder manter autónomo, independente e participativo. É por essa razão que se concorda com Carvalho e Ferreira (2016) que sublinham a necessidade da aprendizagem ao longo da vida que inclua os idosos porque 
só desta forma estão reunidas as condições para que possam atualizar as suas competências e experiências que lhes permita intervir nos problemas e nas dinâmicas sociais. Não se deve escamotear o facto dos adultos idosos terem um manancial riquíssimo de experiências e conhecimentos que foram promovendo e adquirindo ao longo da sua vida e que são um capital extremamente valioso. Por essa razão, Cachioni e Neri (2008) se referem que todas essas experiências e conhecimentos não devem ser consideradas como um impedimento e que os adultos idosos conheçam e aprendam mais coisas com uma aplicação prática e útil para os atuais contextos e necessidades. Carvalho e Ferreira (2016) acrescentam que esta aprendizagem ao longo da vida pode contribuir para uma abertura de maiores horizontes e integração pessoal e social podendo contribuir ainda para a prevenção de declínios prematuros ao nível cognitivo. Em jeito de síntese, apresenta-se a proposta de Cachioni e Neri (2008) que contém as premissas e objetivos para um plano de aprendizagem ao longo da vida que parece perfeitamente ajustada aos adultos mais idosos, a qual deve ser vista como proposta e não uma indicação prescritiva dado que deve ser sempre feita uma avaliação de cada contexto e de cada indivíduo:

- existir uma intencionalidade clara e objetiva;

- haver uma adequação aos participantes (grupo-alvo);

- deve ser consistente de forma a ser contínua e acumulativa com espaços temporais bem definidos;
- promover espaços que privilegiem a intervenção e o envolvimento participado e direto dos adultos idosos partilhando as suas experiências e conhecimentos prévios;

- fomentar todas as condições e contextos para o desejo de aprender $\mathrm{e}$ de continuar a aprender através de estratégias que envolvam as relações interpessoais;

- talvez a questão mais importante: promover e realizar com, para e pelos adultos idosos.

No entanto, como adverte Dias (2012), é também importante que se tenha presente que as condições dos adultos para a aprendizagem é diferente de acordo com as suas caraterísticas biológicas, sociais e psicológicas, tais como: mobilidade; flexibilidade; capacidades cognitivas; capacidades motoras; capacidades sensoriais; memória; atenção... daí ser necessário um maior cuidado nas abordagens, nas estratégias, nos recursos, na logística e nas metodologias. Neste particular, há já quem advogue a necessidade de uma gerontagogia que seja capaz de proporcionar estes cuidados para uma abordagem mais consentânea com os adultos idosos.

\section{Literacia e competência digitais numa sociedade globalizada}

Já se torna um lugar comum referir que na presente sociedade digital as competências adquiridas e/ou a adquirir têm que ser na área do digital. Para o 
efeito Davies et al. (2011) referem que estas competências designadas por e-skills terão que possuir por detrás uma abrangência plural e transdisciplinar no sentido de poderem ser concretizadas de forma adaptativa e colaborativa num contexto transcultural, onde se associa a globalização. As e-skills estarão associadas às seguintes concepções: ser capaz de aceder à informação e, ao mesmo tempo, ser capaz de a recolher através de suportes e/ou plataformas digitais; ter a capacidade de gerir e de organizar essa informação para uma utilização futura; ter presente a necessidade de que a avaliação, a integração, a interpretação e a comparação da informação deva ser feita através de uma diversidade de fontes; ser capaz de promover a criação e a geração de novos conhecimentos através da adaptação e da aplicação da informação; por fim, criar condições para comunicar e transmitir esse novo conhecimento, agora nova informação, para diferentes e variados públicos, utilizando os meios que forem mais ajustados.

Como referem Loureiro e Rocha (2012), estamos numa sociedade digital que designaram por digitally literate que se torna precursora e indutora para uma sociedade que cada vez mais se deve vir a basear no conhecimento: knowledge-based society. Do mesmo modo, já havia por parte de Gilster (1997) a preocupação de, para além de um sentido mais instrumental e técnico, um sentido mais pragmático e útil para que as competências visassem e permitissem a utilização das tecnologias nas rotinas diárias. $\mathrm{Ou}$ ainda como complementa Freitas (2010) ao afirmar a necessidade de se refletir a literacia enquanto prática social. Por essa razão, Vilella e Salvat (2005) são de opinião que as tecnologias digitais impliquem a inclusão de novos instrumentos de aprendizagem com a elaboração de conteúdos diversificados que consigam conciliar o formal e o informal numa formação de cariz digital, onde se realce o seu sentido utilitário devidamente avaliado e refletido. Como ainda refere Gil (2013), esta utilização deve ser assumida numa atitude colaborativa para que se fomentem espaços de comunicação e de interação para as tornar as tecnologias digitais como recursos que permitam resolver situações-problema. $\mathrm{Ou}$, como advoga Castells (2004), torna-se importante para os adultos idosos que esta formação possa evidenciar e potenciar a necessidade de ensinar a aprender.

Esta questão tem sido alvo de uma reflexão crítica no seio da União Europeia, tendo sido publicadas as competências digitais para os cidadãos Europeus. De acordo com a European Union (2016), são definidas 21 competências distribuídas por 5 áreas de competência, designadas genericamente como DigComp's, como podem ser observadas na Figura 6. 
Figura 6 - Áreas de competência e competências digitais (DigComp’s) para os cidadãos da União Europeia..

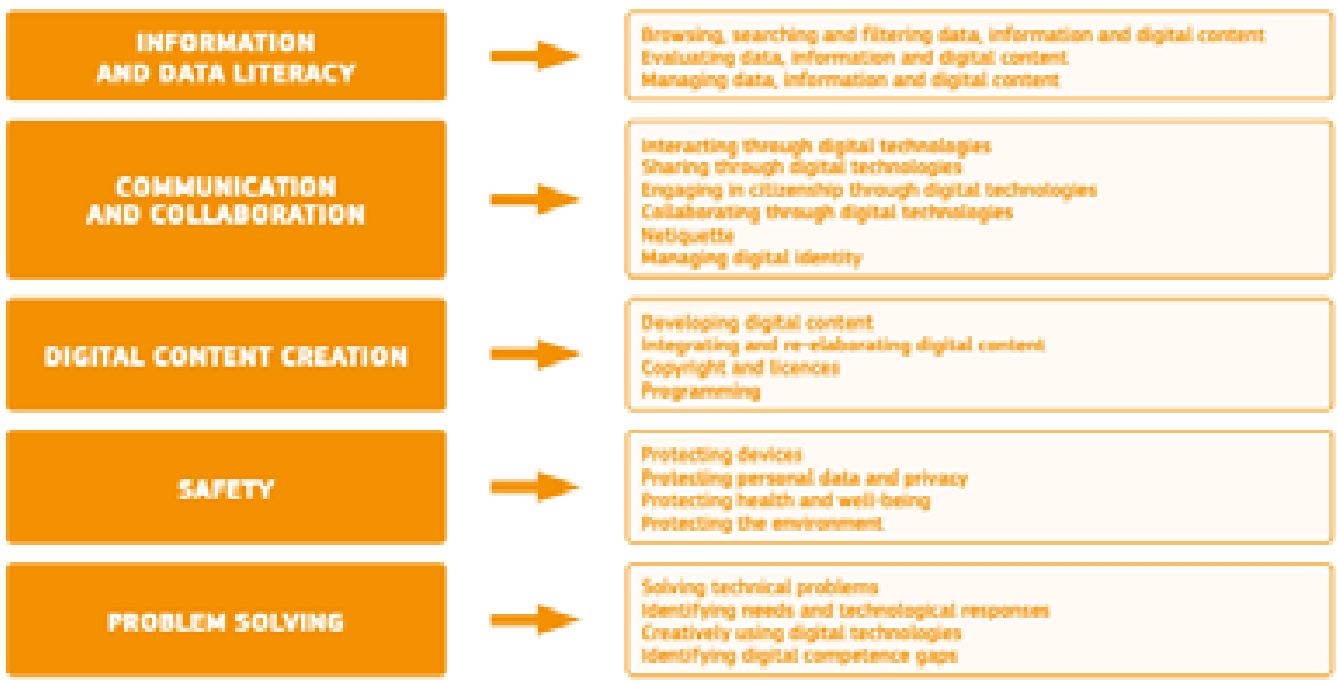

Fonte: European Union (2016).

Numa análise às áreas de competência e respetivas competências, concorda-se com Lucas e Moreira (2017) ao se poder afirmar que as três primeiras áreas de competências (Informação; Comunicação; Criação de conteúdo) serem mais lineares, as áreas quatro e cinco (Segurança e Resolução de problemas) parecem ser de um tipo mais transversal, onde se pode destacar a 'Resolução de problemas' como a área que mais operacionaliza todas as outras. Por outro lado, ainda como referem Lucas e Moreira (2017), a distribuição de competências por cada uma das áreas, tentou ser equitativa, onde as primeiras competências tendem a ter uma associada uma competência mais técnica e aconselham a que este quadro de referência deva ser encarado mais como descritivo do que prescritivo.
Esta questão da literacia digital já tem vários anos de discussão e a problemática já não pretendia restringir-se apenas a um simples acesso e capacidade de utilização dos recursos digitais, mas apelar para uma utilização criativa e crítica (COMISSÃO DAS COMUNIDADES EUROPEIAS, 2007a). A mesma opinião tem Erstad (2010) e Ala-Mutka (2011) ao referirem que o mais importante e o que se deve sobrevalorizar são os conhecimentos, as habilidades e as atitudes em vez do acesso e de uma utilização técnica dos recursos digitais. Varis (2008) é mesmo muito crítico em relação a uma utilização puramente técnica ao afirmar que tal corresponderia a uma simplificação e até a uma certa perda de sentido dado o potencial que as tecnologias digitais encerram em si mesmas. Uma outra dimensão, associada à geração de 
novos conhecimentos, destaca e alerta para uma utilização ética e responsável que tem subjacente o respeito pelos direitos de autor e respetivas licenças de utilização para que não se torne abusiva a utilização sem consentimento dos autores da informação. Por isso, convém novamente reforçar as dimensões das competências digitais ao se concordar com Roberto, Fidalgo e Buckingham (2015) a necessidade de uma passagem de uma literacia funcional, encarando-se as tecnologias apenas com o sentido prático de ferramentas para uma literacia digital crítica onde se encarem as tecnologias como recursos culturais e com uma utilização responsável e ética. Porque, como afirma Nicolescu (2000), as tecnologias digitais promovem poder na atual sociedade tecnológica global e se esse poder é transferido e conferido para as nossas mãos na utilização de um teclado, vem implicar que o que escrevemos e o que dizemos, seja respaldado por uma forte e consolidada formação ética.

Como de poderá depreender as questões que envolvem as competências digitais deverão ter um alcance maior, um alcance social e operacional no sentido de poderem ver satisfeitas necessidades individuais e, ao mesmo tempo, também necessidades coletivas. Mas para que tal possa ocorrer é fundamental e necessário, tal como adverte Erstad, 2007) que todos sejam capazes de o fazer. Caso contrário, poderão ser geradas desigualdades sociais entre aqueles que dominam e adquiriram competências digitais - infoincluídos - e aqueles que não as dominam - infoexcluídos. $\mathrm{Ou}$ seja, aqueles que podem tirar proveitos e aqueles que ficam impedidos de usufruírem desses proveitos. Atendendo a estas questões, Pereira (2011) é de opinião que devam ser feitos esforços para que todos os cidadãos tenham uma participação ativa nas discussões e nas deliberações para que possam, de forma efetiva, estar capacitados para cumprirem os seus direitos e deveres, de uma forma cabal, adquirindo competências digitais. E, como ainda afirmam Faria, Ramos e Faria (2012, p. 432), de forma bastante objetiva, a literacia digital “(...) deve abranger os adultos e mesmo os idosos como forma de contribuir para o seu desenvolvimento pessoal e integração social." Uma investigação realizada por Pereira e Neves (2011) veio demonstrar que a idade não era condição que justificasse a exclusão do mundo digital e que, pelo contrário, deverá ser considerada esta questão com uma motivação extra para que se concertem e desenvolvam iniciativas para a melhoria da qualidade de vida dos adultos idosos.

\section{Premissas para a inclusão digital e social dos adultos idosos}

A Comissão das Comunidades Europeias (2005) já há muito tempo que se vem preocupado com as questões associadas à infoinclusão, dando-se como exemplo a iniciativa $i 2010$ - Uma sociedade da informação europeia para o crescimento e emprego com o objetivo simultâneo de promover uma abordagem política proativa para estimular os mercados e 
promover a sociedade do conhecimento, de forma a incluir a aprendizagem ao longo da vida, a criatividade e a inovação. Nesta iniciativa pretendiam-se abranger três vertentes: garantir que as TIC beneficiassem todos os cidadãos; melhorar a qualidade, a relação custo/ eficácia e a acessibilidade aos serviços públicos; e, num sentido mais lato, melhorar a qualidade de vida. Um outro objetivo era o de se promover uma iniciativa europeia para a infoinclusão para promover a igualdade de oportunidades, maiores e melhores qualificações na área das TIC e diminuir as fraturas regionais. Na sequência a Comissão das Comunidades Europeias (2007b) avançou com o plano Envelhecer bem na sociedade da informação - Tecnologias da Informação e das Comunicações e Envelhecimento sente-se que há um sentimento de há muito para fazer e que urge a tomada de medidas no sentido das TIC serem o garante para uma melhoria da qualidade de vida para os adultos idosos. Neste sentido, pretende-se levar a efeito estes objetivos em três áreas distintas:

1) Envelhecer bem no trabalho: de forma a permanecerem mais ativos e produtivos através das TIC por estas poderem propiciar práticas inovadoras;

2) Envelhecer bem na comunidade: promoção de redes sociais e acesso aos serviços públicos para que se reduza o isolamento social doa adultos idosos, em especial, nas zonas rurais e de pequena densidade populacional;
3) Envelhecer bem em casa: pretende-se que os adultos idosos possam permanecer por mais tempo nas suas casas com níveis de maior autonomia, de independência e, talvez mais importante que tudo, com dignidade.

Neste plano destaca-se ainda a noção de que se devem compreender os idosos, ou seja, ter a consciência de que as necessidades e as utilizações digitais por parte dos adultos idosos devem ser pensadas e centradas neles mesmos. Daí haver a referência à necessária capacitação dos idosos, mas, há uma consciência das dificuldades e obstáculos vigentes, dado que não existe uma abordagem sistemática do desenvolvimento do mercado para estes consumidores o que leva a um incremento dos custos e na escassez de oferta. Acrescenta-se ainda a fraca utilização da internet por este grupo social e também o facto de não ter havido uma educação/formação onde também estivessem equacionadas dimensões éticas e psicológicas.

As questões já discutidas em torno da literacia digital pretenderam tornar claro que esta concepção é muito mais abrangente e holística e com profundas repercussões na vida dos cidadãos. Para o efeito, tal como afirmam Roberto, Fidalgo e Buckingham (2015, p. 52), as tecnologias digitais são o motor para o desenvolvimento económico, social cultural e, obviamente, tecnológico. E, por essa razão, a literacia social deve ter uma abrangência universal para se criem espaços de reflexão ativa e crítica de cidadania para que se possa comba- 
ter a exclusão, no seu sentido mais lato “(...) é fundamental conhecer, refletir e participar e estas parecem ser necessidades transversais às diferentes gerações digitais." Pois, só desta forma se poderão assegurar as condições para que estabeleça uma sociedade mais participativa e com níveis de uma maior coesão social. Neste sentido, concorda-se com Patrocínio (2001) quando afirma que nesta sociedade digital globalizada a cidadania que se exerce deixa de ter uma dimensão local associada à sua geografia local/ regional de residência para passar a ter uma dimensão global, a que designou por se passar a ser um cidadão glocal. $\mathrm{E}$, prova desta assunção, tem a ver com a inter-relação e a com a imersão entre o físico e o digital que se materializa, por exemplo, nas interações geradas através das SMS e de e-mails, num espaço e num contexto que se passou a designar por ciberespaço.

Neste novo contexto social com uma geografia global pode-se afirmar que nos encontramos num planeta interativo (MAYOR, 2001). E, é nesta nova geografia global e interativa que se tem vindo a observar um conjunto de movimentos globais das mais diversas índoles (políticas, económicas, religiosas, sociais...) com poder de influenciar e de fazer vingar opiniões e/ou comportamentos através do Twitter, de blogues e de redes sociais digitais. Mas, estas pressões e influências só são concretizadas para quem possui uma literacia digital adequada o que faz com que a maioria dos adultos idosos que são infoexcluídos fica à margem e, por essa razão, deixam de ter poder reivindicativo, sendo ignorados. Desta feita, como refere Patrocínio (2001, p. 166) o "(...) acesso à fruição da contemporaneidade que é uma das condições de coesão social" fica em causa por parte de quem é infoexcluído. E, ainda para reforçar este aspeto, concorda-se com Rifkin (2001, p. 192) quando afirma que “(...) muito da civilização humana irá ocorrer nos mundos eletrônicos do futuro. A questão do acesso, então, torna-se uma das considerações mais importantes da nova era." Estas novas realidades levam-nos para outro tipo de cidadãos, para cidadãos que consigam usufruir do ciberespaço a que Hauben e Hauben (1996) começaram por designar por netizen (ou por cibercidadão) como sendo aquele cidadão ao qual se associa uma pertença não-geográfica, mas antes a uma pertença global.

Para finalizar deve reter-se a afirmação de Pérez Tornero (2003, p. 47), a qual sintetiza a reflexão crítica aqui apresentada e que se espera que venha a ter sucesso: "El derecho a la alfabetización digital es un aspecto nuevo del derecho a la educación, teniendo en cuenta, sin embargo, que la educación digital ha de extenderse a todas las edades para no dejar fuera a nadie: ancianos, adultos y niños." Pois, caso contrário, entendendo-se que os jovens, também conhecidos por nativos digitais, portadores de competências digitais, em contraponto com a grande maioria dos adultos idosos, desprovidos dessas competências digitais, venham a provocar, tal como referia Negroponte (1996), não somente uma divisão social entre os que são ricos-em-informação e 
os que são pobres-em-informação, entre aqueles que têm e os que não têm... mas a divisão cultural vai ser a das gerações com todos os perigos e fragilidades que tal vai acarretar num mundo cada vez mais envelhecido, pondo em causa uma sociedade que se pretende ser mais justa, mais equitativa e mais coesa!

\section{Lifelong learning and digital training of the elderly}

\section{Abstract}

The increase in life expectancy has resulted in a gradual aging of society, with older adults aged 65+ years, and increasing in the more developed countries. This reality has led to a greater number of retired people who received their training in a very different context from the current one. As is evident, the advancement of digital technologies and their applications have promoted changes in the daily routines of citizens. In this context, a critical and reflective discussion about the role of lifelong learning and the requirements for adequate digital training is appropriate, as well as providing conditions for a more adjusted social inclusion of the elderly.

Keywords: Digital literacy. Elderly adults. Infoinclusion. Lifelong learning. Social inclusion.

\section{Referências}

ALA-MUTKA, K. Mapping digital competence: towards a conceptual understanding. Sevilha: JRC-IPTS, 2011.

CACHIONI, M.; NERI, A. Educação e velhice bem-sucedida no contexto das universidades da terceira idade. In: NERI, A.; MASSUDA, M. (Orgs.). Velhice bem-sucedida. aspectos afetivos e cognitivos. São Paulo: Papirus Editora, 2008. p. 29-50.

CASTELLS, M. A Galáxia Internet. Lisboa: Fundação Calouste Gulbenkian, 2004.

CONSELHO NACIONAL DE EDUCAÇÃO. Estado da Educação 2016. Lisboa: CNE, 2016. Disponível em: <https://www.cnedu. pt/content/noticias/CNE/CNE-EE2016_web. pdf>. Acesso em: 21 maio 2018.

COMISSÃO DAS COMUNIDADES EUROPEIAS. Tornar o espaço europeu de aprendizagem ao longo da vida uma realidade. Bruxelas: Serviço das Publicações Oficiais das Comunidades Europeias, 2001.

COMISSÃO DAS COMUNIDADES EUROPEIAS. i2010 - Uma sociedade da informação europeia para o crescimento e emprego. Bruxelas: Serviço das Publicações Oficiais das Comunidades Europeias, 2005.

COMISSÃO DAS COMUNIDADES EUROPEIAS. Comunicação da Comissão. Educação de adultos: nunca é tarde para aprender. Bruxelas: Serviço das Publicações Oficiais das Comunidades Europeias, 2007. Disponível em: <https://eur-lex.europa.eu/legal-content/ PT/TXT/PDF/?uri=CELEX:52006DC0614\&from $=\mathrm{PT}>$. Acesso em: 20 maio 2018.

COMISSÃO DAS COMUNIDADES EUROPEIAS. Uma abordagem europeia da literacia mediática no ambiente digital. Bruxelas: Serviço das Publicações Oficiais das Comunidades Europeias, 2007a.

COMISSÃO DAS COMUNIDADES EUROPEIAS. Envelhecer bem na sociedade da informação - Tecnologias da Informação $e$ das Comunicações e Envelhecimento. Bruxelas: Serviço das Publicações Oficiais das Comunidades Europeias, 2007b.

COMUNIDADES EUROPEIAS. Competências-chave para a Aprendizagem ao Longo da Vida - Quadro de Referência Europeu. Luxemburgo: Serviço das Publicações Oficiais das Comunidades Europeias, 2007. 
DAVIES, A.; FIDLER, D.; GORBIS, M. Future work skills 2020. Institute for the Future: University of Phoenix Research Institute, 2011.

DIAS, I. O uso das tecnologias digitais entre os seniores: motivações e interesses. Sociologia, Problemas e Práticas, v. 68, p. 51-77, 2012.

ERSTAD, O. Conceiving digital literacies in schools - Norwegian experiences. Proceedings of the 3rd International workshop on Digital Literacy, p. 1-10. 2007. Disponível em: <http://ftp.informatik.rwth-aachen.de/ Publications/CEUR-WS/Vol-310/paper01. pdf>. Acesso em: 22 maio 2018.

ERSTAD, O. Educating the Digital Generation. Nordic Journal of Digital Literacy, p. 56-702010.

EUROPEAN UNION. The European Digital Competence Framework for Citizens. Luxembourg: Publications Office of the European Union, 2017. Disponível em: < https://ec.europa.eu/social/BlobServlet?docId=15688\&langId=en\#: : text=The $\% 20$ EU\%20has\%20developed\%20the, their\%20 knowledge\%2C\%20skills\%20and\%20attitudes.>. Acesso em: 18 maio 2018.

EUROSTAT. The EU in the World - 2016. Luxembourg: European Union, 2016. Disponível em: <https://ec.europa.eu/eurostat/ documents/3217494/7589036/KS-EX-16001-EN-N.pdf/bcacb30c-0be9-4c2e-a06d-4b1daead493e>. Acesso em: 22 maio 2018.

FARIA, P.; RAMOS, A.; FARIA, A. De que falamos quando falamos em literacia digital? Um estudo exploratório baseado em revisão sistemática de literatura. Atas do II Congresso Internacional TIC e Educação. Porto: Universidade do Porto, 2012, p. 419-436.

FOX, T.; MACLEOD, S.; CHANDLER, M.; KWAAW, E. Report on a literature review of reforms related to the European Framework of key Competences for lifelong learning and the role of the framework in these reforms. Brussels: European Commission, 2017.
FREITAS, M. Letramento digital e formação de professores. Educação em Revista, v. 26, n. 3, p. 335-352, 2010.

GIL, H. Ambientes 'Personalizados' de aprendizagem de adultos idosos: a potencial relevância das TIC. In Atas da VIII Conferência Internacional das TIC na EducaçãoDesafios / Challenges. Braga: Universidade do Minho, 2013, p. 184-191.

GILSTER, P. Digital Literacy. San Francisco: John Willey \& Sons, 1997.

GUERCIA, C. Algumas reflexiones pedagógicas sobre la educación del ócio com personas mayores. In: ORDUNA, G.; NAVAL, E. (Eds.). Gerontologia Educativa. Barcelona: Ariel Educación, 2001, p. 185-206.

GUIMARÃES, P. A utilidade da educação de adultos: a aprendizagem ao longo da vida na União Europeia e a política de educação e formação de adultos em Portugal. Laplage em Revista, Sorocaba, v. 2, n. 4, p. 36-50, 2016.

HAUBEN, M.; HAUBEN, R. Netizens: On the History and impact of Usenet and the Internet, 1996.

LIMA, L. A Educação de adultos em Portugal (1974-2004). In: CANÁRIO, R.; CABRITO, B. Educação e formação de adultos. Mutações e convergências. Lisboa: Educa, 2005, p. 31-60.

LOUREIRO, A.; ROCHA, D. Literacia digital e literacia da informação - Competências de uma era digital. In: Atas do II Congresso TIC e Educação. Porto: Universidade do Porto, 2012, p. 2726-2738.

LUCAS, M.; MOREIRA, A. DigComp - Quadro Europeu de Referência para a Competência Digital. Documento de Trabalho. Aveiro: Universidade de Aveiro, 2017.

MAYOR, F. Desenvolvimento endógeno e governação democrática. In: AAVV 2001. Globalização, Desenvolvimento e Equidade. Lisboa: Fundação Calouste Gulbenkian, 2001, p. 195-198.

NEGROPONTE, N. Ser Digital. Lisboa: Editorial Caminho, 1996. 
NICOLESCU, B. O manifesto da transdisciplinaridade. Lisboa: Hugin, 2000.

PACHECO, J. Currículo, Aprendizagem e Avaliação. Uma abordagem face à agenda globalizada. Revista Lusófona da Educação, n. 17, p. 75-90, 2011.

PATROCÍNIO, J. Tornar-se pessoa e cidadão digital - Aprender e formar-se dentro e fora da escola na sociedade tecnológica globalizada. Tese de Doutoramento em Ciências da Educação/Especialidade de Educação e Desenvolvimento. Lisboa: Universidade Nova de Lisboa, 2004.

PEREIRA, C.; NEVES, R. Os idosos e as TIC - competências de comunicação e qualidade de vida. Revista Kairós Gerontologia, São Paulo, v. 14, n. 1, p. 5-26, 2011.

PEREIRA, L. Conceções da literacia digital nas políticas públicas - estúdio a partir do Plano Tecnológico da Educação. Tese de Doutoramento em Ciências da Comunicação - Especialidade Educação para os Media. Braga: Universidade do Minho, 2011.

PÉREZ TORNERO, J. Comprender la alfabetizacíon digital. Informe final EAC/76/03. Barcelona: UAB, 2003. Disponível em: $<$ http://www.gabinetecomunicacionyeducacion.com/files/adjuntos/Comprender\%20 la\%20alfabet izaci_n\%20digital_informe\%20 final_131204.pdf $>$. Acesso em: 17 de maio de 2018.

PIRES, A. Como vamos melhorar a educação nos próximos anos, tendo em vista construir Portugal mais moderno e mais justo? In AAVV, Aprendizagem ao longo da vida no debate nacional sobre educação. Lisboa: Conselho Nacional de Educação, 2007, p. 75-83.

RIFKIN, J. A era do acesso: a transição de mercados convencionais para networks e o nascimento de uma nova economia. São Paulo: Makron Books, 2001.

ROBERTO, M.; FIDALGO, A.; BUCKINGHAM, D. De que falamos quando falamos em infoexclusão e literacia digital?
Perspetivas dos nativos digitais. Observatório Journal, v. 9, n. 1, p. 43-54, 2015.

SITOE, R. Aprendizagem ao Longo da Vida: Um conceito utópico? Comportamento Organizacional e Gestão, v. 12, n. 2, p. 283-290, 2006.

STATISTA. The Statistics Portal. 2017. Disponível em: <https://www.statista.com/ statistics/265759/world-population-by-age-and-region>. Acesso em: 20 maio 2018.

VARIS, T. European and global approaches to digital literacy. Nordic Journal of Digital Literacy, v. 3, n. 1, p. 53-60, 2008.

VILLELA, X.; SALVAT, B. Uso y abuso de los vídeojuegos. Comunicación y Pedagogia, 208, 2005. Disponível em: <http://xtec.cat/ ãbernat/articles/vilella-gros.pdf $>$. Acesso em: 20 de Maio de 2018:

WHO. World Health Statistics - 2018-Monitoring health for the sustainable development goals. ISBN 978-92-4-156558-5. Switzerland: World Health Organization, 2018. 